\title{
A Pebble, a Camera, a Man Who Turns into a Telegraph Pole
}

\section{John Frow}

Moving house while I was writing this paper, I have been working in an unusually intense way with physical things: sanding back wooden floors, shifting cartons of books, sealing a window frame with putty, tightening the rings on a washing machine hose ... Callused on my fingers, this is a kind of knowledge different from intellectual knowing (which is, nevertheless, always a matter of paper and ink and electric currents running through machinery). Old skills of understanding the world with my hands come back to me. And I experience the sheer singularity of its things: this nameless, almost indescribable Odradek of a thing, for example, an asymmetrical grooved and slotted bit of fractionally cylindrical metal that ties two planks of bookshelf together around a projecting, greased metal screw. Someone designed it, gave it its mysteriously precise logic, perhaps even has a name for it; but to me it's purely strange.

That sense of strangeness is one kind of beginning to an essay on things, but it's one that can get caught up all too easily in a supposition of the thing's ontological purity and in the nostalgia for a world of simple objects that talk about things so often betrays. That nostalgia permeates almost all contemporary thinking about things. It is classically located in Heidegger's harkening to the things of a stable and preindustrial rural world ('a stone, a clod of earth, a piece of wood ... Lifeless beings of nature and objects of use') ${ }^{1}$ and to the 'authentic experience' of thingness

1. Martin Heidegger, 'The Origin of the Work of Art', Poetry, Language, Thought, trans. Albert Hofstadter (New York, 1971), p. 21; hereafter abbreviated ' $O$ '. 
by the Greeks, an experience of 'the Being of beings in the sense of presence' which has been lost to Western philosophy in the process of translating Greek thought into the Latin categorization of thingness as the union of substance with accidents, or as the unity of a manifold of sensations, or as formed matter ('O', p. 23). If the impossible scope of this topic is in some sense imaginable, however, it's because it is narrowed by the way certain questions tend to press more urgently on us-to shape a certain corner of the amorphous space inhabited by the disciplines that think about cultural thingness. These questions have to do with our habitation of the aftermath of a theoretical paradigm which sought to imagine the world rigorously in terms of the play of representations and rigorously to exclude the sleight of hand by which a beyond of representation is posited in such a way that representation could be measured against it. Our problem is that beyond.

Which is perhaps above all a problem about the writing or imaging of things in texts. This is "Pebble," a poem by the Polish poet Zbigniew Herbert:

The pebble

is a perfect creature

equal to itself

mindful of its limits

filled exactly

with a pebbly meaning

with a scent which does not remind one of anything

does not frighten anything away does not arouse desire

its ardour and coldness

are just and full of dignity

I feel a heavy remorse

when I hold it in my hand

and its noble body

is permeated by false warmth

John Frow is Regius Professor of Rhetoric and English Literature and Director of the Institute for Advanced Studies in the Humanities at the University of Edinburgh. His most recent books are Time and Commodity Culture (1997) and (coauthored with Tony Bennett and Michael Emmison) Accounting for Tastes: Australian Everyday Cultures (1999). 
- Pebbles cannot be tamed

to the end they will look at us

with a calm and very clear eye ${ }^{2}$

Like the remote beloved of courtly poetry, the 'perfect creature' generates a drama of longing, of attempted conquest, and of refusal. In the first act the pebble is described through a series of divisions between subject and predicate which are, however, in relations of such absolute equivalence that the division again disappears. Thingness is the tautologous identity of subject and predicate. If we are to understand its entelechy, the perfection of its necessary being, we must suppose it to have an intention regarding its disposition within its own (spatial and moral) limits, to have a meaning which is exactly and entirely coextensive with it, to have a scent which can be defined only as the negation of all the properties of scent, to have equal and opposite emotions which entirely befit its status as an emotionless entity. In the second act of the story, the speaker, whom we must suppose to be disturbed by the inhuman perfection and thus inaccessibility of the pebble, seeks to impose his emotions on it but succeeds only in transmitting a warmth which cannot touch the pebble's heart; realizing this, the speaker feels remorse. The third act records this defeat: the self-identity of the pebble renders it invulnerable to domination. It is unresponsive to human emotion. It returns the human gaze without fear and with a rationality that refuses the false warmth with which we try to awaken it to a sense of our own existence. Like the remote beloved, the pebble cannot care for us.

Why does the pebble return my gaze? But 'return' is the wrong way of putting it: the pebble does no more than look at me, unseeing, and it does so because to be so purely a thing, so deeply withdrawn from capture by others, is to pass into that mode of irreducibility and unknowability that we call the subject. Its look is the very form of that presenceto-self which cannot, as such, be an object for another. This is the paradox of any fascination with the thingness of things: that things posited in themselves, in their distinctness from intention, representation, figuration, or relation, are thereby filled with an imputed interiority and, in their very lack of meaning, with 'a pebbly meaning' which is at once full and inaccessible. (Think of the final minutes of Antonioni's L'Ellipse, a series of slow, wordless, stylized shots that shift us from a world of stories to a world of things-scaffolding, a fence, a leaking bucket, a sprinkler, a woman waiting for a bus, rustling leaves, a sodium light - which had until then been the background for human action and which now, revealed in the plenitude of their being, at once enigmatic and luminous, are seen to be the point of the film, its true actors, the ones that look at us.) Sartre 
expresses this paradox in the following way: being in-itself, he writes, 'does not refer to itself as self-consciousness does. It is this self. It is itself so completely that the perpetual reflection which constitutes the self is dissolved in an identity. That is why being is at bottom beyond the self. Yet, at the same time, 'in fact being is opaque to itself precisely because it is filled with itself. This can be better expressed by saying that being is what it is': 'equal to itself/mindful of its limits'.

This paradox and the drama that surrounds it constitute a discourse which flourished early in the last century, both in the phenomenological reduction which seeks to bracket things in their singularity and in a central tradition of poetic (and to a degree novelistic) writing which sought, in reaching back to the thingness of things, to free them from their merely instrumental status in a world of human uses: the poetry of Rilke's Neue Gedichte, of William Carlos Williams's imagism, of Neruda's Odas Elementales, of Ponge's Le Parti pris des choses. The thingness of things posited in this discourse-its stuff, its matter, whatever it is that subsists behind and beneath accident, contingency, time, and the weave of knowledges and uses that give them to me-is like a dream of immortality, of inherence and persistence beyond all change. That's why the vision of thingness so quickly becomes a vision of God (Stan's epiphanic glimpse of the numinous in a gob of spittle in The Tree of Man, for example).$^{4}$ And it's why the true role of Things, of underlying thingness, is to be the mirror of our souls, the object that makes us a subject, that makes us real. That's why the auratic thing returns my gaze: it is myself that I see, looking back in astonishment at its mirror image, myself. Hence Lacan's thesis that the gaze is inscribed in the world, always already looking at me; that the gaze 'imagined by me in the field of the Other' forms me as other to myself in the same movement as that in which I 'recognize' the Thing that sees me. ${ }^{5}$

Endowed with an interiority and a memory, things become stories. This is the description of a throwaway camera which, towards the end of Richard Powers's novel Gain, stands in for the heroine's death from cancer:

The camera jacket says: "Made In China With Film From Italy Or Germany" The film itself accretes from more places on the map than emulsion can cover. Silver halide, metal salts, dye couplers, bleach fixatives, ingredients gathered from Russia, Arizona, Brazil, and underwater seabeds, before being decanted in the former DDR. Camera in a pouch, the true multinational: trees from the Pacific Northwest and the southeastern coastal plain. Straw and recovered wood scrap from Canada. Synthetic adhesive from Korea. Bauxite

3. Jean-Paul Sartre, Being and Nothingness: An Essay on Phenomenological Ontology, trans. Hazel E. Barnes (London, 1957), p. lxv.

4. See Patrick White, The Tiee of Man (Harmondsworth, 1961), p. 476.

5. Jacques Lacan, The Four Fundamental Concepts of Psycho-Analysis, trans. Alan Sheridan, ed. Jacques-Alain Miller (London, 1977), p. 84. 
from Australia, Jamaica, Guinea. Oil from the Gulf of Mexico or North Sea Brent Blend, turned to plastic in the Republic of China before being shipped to its mortal enemies on the Mainland for moulding. Cinnabar from Spain. Nickel and titanium from South Africa. Flash elements stamped in Malaysia, electronics in Singapore. Design and colour transfers drawn up in New York. Assembled and shipped from that address in California by a merchant fleet beyond description, completing the most heavily choreographed conference in existence. ${ }^{6}$

Literally a black box, the camera unseals and unfolds itself as a matrix of histories and geographies. To recover things is to find again these lost stories, the lines of people and places that converge in them and that have been obscured by the thickening of the surfaces of things, the selfevidence that informs them with presence pure and simple.

The strongest version of this story of the bad enchantment of the world of things is the Marxist theory of commodity fetishism. ${ }^{7}$ The concept displaces the enlightened critique of religion ('primitive' and especially animistic religion, but for enlightened thought all religion is primitive) into the critique of political economy. ${ }^{8}$ With the advent of widespread commodification, the social relation between people which is the reality of human work and exchange comes to assume the 'fantastic' form of a relation between things. The structure of the commodity, in which the particularity of use-value is subordinated to the abstract universality of exchange-value, effects a mystified conversion of 'the social characteristics of men's own labour' into what seem to be 'objective characteristics of the products of labour themselves'. ${ }^{9}$ Persons and things both become thinglike, and the causal relation between work and value is inverted. Whereas the related Marxist concept of alienation foregrounds a transcendental notion of the person, the concept of commodity fetishism turns its focus to the opposition between a simple and a complex social relation, to an opposition between the immediacy of relations among direct producers of use-values and the highly mediated and abstract structure of commodity relations. What characterizes things in capitalist production and exchange is thus not at all their thingness but the opposite, an abstractness which takes the form of a dense materiality. Insofar as the Marxist account of the commodity form is an analysis of semiotic value, its tendency is to oppose use-value to exchange-value as matter to representation and as immediacy to mediation. More broadly: despite the

6. Richard Powers, Gain (New York, 1998), pp. 347-48.

7. The following paragraph draws on an argument made in my Time and Commodity Culture (Oxford, 1997), pp. 141-42.

8. See William Pietz, 'Fetishism and Materialism: The Limits of Theory in Marx', in Fetishism as Cultural Discourse, ed. Emily Apter and Pietz (Ithaca, N.Y., 1993), pp. 130-31.

9. Karl Marx, Capital: A Critique of Political Economy, trans. Ben Fowkes, 3 vols. (London, 1976), 1:164-65. 
force of its historical and relational conception of the commodity form, its conceptual ground is a myth of presence which leads it to understand this form on the one hand as the alienation of the integrity of the person and on the other as the replacement of the simplicity, transparency, and immediacy of the use-value of things with a complex system of representations.

Leah Hager Cohen spells out what we might take to be the consequences of this replacement. At the core of commodity fetishism is an 'erosion of objects' singularity' by the abstract equivalence of exchangevalue. ${ }^{10}$ Things are 'sealed off from their origins, ensconced from their own true stories, which are the stories of people, of work, of lives' ( $G, \mathrm{p}$. 13). Her own project of tracing the stories that lie hidden within the everyday commodities she consumes-paper, glass, coffee beans-is explicitly an act of restoration of a kind of knowledge of things that has been lost with the passing of traditional ways of life:

Once, we could not help but know what piece of earth the potatoes on our dinner plate came from. We knew whose hand shaped and fired the plate. We knew who cobbled our shoes, and whose cow was slaughtered to provide the leather. We knew from which spring, or well, or rain barrel our water was dipped. In many parts of the world people still know these things, but in what we term the developed nations of the earth such facts have gone hazy, have taken on the properties, almost, of fairy tales: the notion of connections seems charming, but not quite real. [G, p. 13]

In that lost world the human is more human, things more thinglike because of the immanence of human stories to things. This is a knowledge that can be recovered by a labor of attention: 'Everywhere you rest your eyes, invisible stories blossom' ( $G$, p. 289).

Such attention takes place within a discourse that is at once humanist and epistemological; to be fully human is to know that things are made up of human stories, is to penetrate the layers of abstraction beneath which these true stories are concealed. Persons and things are mutually constituted in the representations of things. Yet we might note an ambivalence in Cohen's argument: what she seeks to restore is precisely not the singularity of things (it is rather the fetish which is truly singular) but the network of human relations that compose them. Things, in her account, are entirely made up of the stories that thread them through with meaning and value, making them entirely reducible to human representations. The throwaway camera is at once so rich with convergent destinies that it can take the place of the novel's dying heroine and so trivial in itself that it is designed for nothing except to be discarded. All opposites are revers- 
ible in this imaginary of the thing, stretched taut across the dialectic of abstract equivalence and human story, and of an otherness so complete that it becomes, again, the same. But might it be possible to evade this dialectic in order to imagine a world in which persons and things are partly strangers and partly kin? In which we recognize that 'the question of things, even the question whether they are, is inseparable from a question about what they do, or what can be done with them'?"1 Let us start again.

In a small town to the west of Sydney, a Greek owns a café in the main street. His daughter waits on the tables; she is said to have a winedark stain on her body, a secret 'so zealously guarded no man had managed to report its details' ${ }^{12} \mathrm{~A}$ travelling salesman comes to town; he is attracted to the sullenness of the waitress and to the secret of her body and decides not to leave town until he has seen it. One night he goes behind the café and watches through her bedroom window as she undresses. As she turns naked towards him he steps back and 'something solid met him from behind'; his arms disappear into his sides, and 'he felt himself merge into something altogether hard and straight; unusually tall.' ${ }^{3}$ His head becomes cold, he begins to hear voices; he has turned into a telegraph pole, fashioned from karri and blackened at the base by the stain which has been transferred from the waitress, of whose intermittent nakedness he now has a clear view in all weathers. ${ }^{14}$

The story, from Murray Bail's Eucalyptus, fuses two myths from Ovid: the story of Actaeon and Diana (told earlier in the novel in a purer form as the story of Young Molloy who watches the novel's heroine, Ellen, pissing by the river, and who then has a smash on his motorbike and loses his sight), ${ }^{15}$ and the story of Daphne and Apollo-in Horace Gregory's translation: ${ }^{16}$

-as she spoke

A soaring drowsiness possessed her; growing

In earth she stood, white thighs embraced by climbing

Bark, her white arms branches, her fair head swaying

In a cloud of leaves; all that was Daphne bowed

In the stirring of the wind, the glittering green

Leaf twined within her hair and she was laurel-

which in turn is reminiscent of Rilke's 'Orpheus. Eurydice. Hermes.' where Eurydice, already growing more and more remote ('Sie war in

11. Bill Brown, 'How to Do Things with Things (A Toy Story)', Critical Inquiry 24 (Summer 1998): 936-37.

12. Murray Bail, Eucalyptus (Melbourne, 1998), p. 193.

13. Ibid., p. 194.

14. See ibid., p. 195.

15. See ibid., p. 48.

16. Ovid, Metamorphoses, trans. Horace Gregory (New York, 1958), 1.546-52, p. 46. 
sich'), is 'so full of her great death . .. that she could understand nothing'. 'Sie war schon Wurzel'; Eurydice is transformed into the same remote otherness as Daphne and the commercial traveller. ${ }^{17}$

That otherness is what the discourse of thingness seeks and fails to apprehend as a mode of being not subject to human will. It seeks to free things from the instrumental status which ties them to human being and thus to endow them with a language of their own; and the effect of this is then to return them, as quasi subjects, to the human world. The pebble is endowed with a subjectivity, the camera with a historical and geographical memory. For Gadamer the problem of our relation to things is that 'we are not at all ready to hear things in their own being, that they are subjected to man's calculus and to his domination of nature through the rationality of science'. ${ }^{18}$ 'Things' here implicitly means naturally occurring or at least simple things rather than complex technical or aesthetic objects. If thinking about thingness has, throughout the history of philosophy, been systematically distorted by the privilege given to such simple bounded entities - if stones, clods of earth, tables, and pots are taken to be somehow more thinglike than machines or buildings or works of art, or than immaterial entities such as time or a dream or the Chrysler corporation-this is above all a problem of examples and their role in foregrounding certain sets of logical entailments over others. Examples are pregnant particularities, 'cases' of the real proposed in such a way that certain more general conclusions can be drawn from their peculiar features; they constitute a 'paradigm' in the Aristotelian sense of an 'instance serv[ing] as vector pointing to a principle or conclusion' but also in the sense that they crowd out other ways of exemplifying some domain of reality. ${ }^{19}$ Gadamer's world must satisfy two demands: that for the existence of an order of things independent of the order of the human and for the existence of a common sphere allowing for a passage between these two orders. What allows us to apprehend the purity of simple things in an otherness which nevertheless unfolds itself to us is language. Even in a world becoming increasingly technical, a world in which things 'are simply vanishing, and only the poet still remains true to them' ('N', p. 71 ), it is yet possible to speak of a language of things, as long as we 'remember what things really are, namely, not a material that is used and consumed, not a tool that is used and set aside, but something instead

17. Rainer Maria Rilke, 'Orpheus. Eurydike. Hermes.' Neue Gedichte, in Werke, 3 vols. (Frankfurt am Main, 1966), 1: 300, 301. Eurydice's becoming-root directly recalls the transformation of Daphne's feet into the roots of a tree: 'pes modo tam velox pigris radicibus haeret' (Ovid, Metamorphoses, 1.551, p. 46).

18. Hans-Georg Gadamer, 'The Nature of Things and the Language of Things', Philosophical Hermeneutics, trans. and ed. David E. Linge (Berkeley, 1976), p. 71; hereafter abbreviated ' $\mathrm{N}$ '.

19. Alexander Gelley, Unruly Examples: On the Rhetoric of Exemplarity (Stanford, Calif., 1995), p. 1. 
that has existence in itself and is "not forced to do anything," as Heidegger says' ('N', pp. 71-72). There is a kind of lack of faith in the way we fail to attend to things, to their inherent speech, instead rendering them the mere instruments of our will. The metaphor of force here is a metaphor of rape: to use is to violate. Yet Gadamer has no wish to restore a simple dichotomy of the human and the nonhuman, a dualism of 'subjectivity and will, on the one hand, and object and being-in-itself, on the other' ('N', p. 74). Whereas classical metaphysics seeks a mediation of these poles in a theological notion of the preexistent correspondence of soul and world, and Marxism in the concept of praxis, Gadamer supposes that it is finally language which effects this mediation in its reconciliation of the language of things with the fact of the 'fundamentally linguistic character of our experience of the world' ('N', pp. 77-78).

Bail's story, however, posits no such separate but reconcilable being of things and speaking souls. It allegorises a world in which a commercial traveller is also a telegraph pole, and the telegraph pole takes on the human capacity to listen to the messages that pass through it and to peer through a bedroom window. Standing like the traveller's erect penis in the darkness outside, it looks and listens and desires and is neither wholly one thing nor the other. The fusion is never complete. Eurydice is constantly on the verge of becoming a root but does not lose her human shape. In the world of this story, the deep metaphysical opposition, the tied dichotomy of difference and mutual constitution as between things and representations and between humans and nonhumans, becomes flattened; difference in kind between commercial travellers and telegraph poles gives way to a mixing in which things and persons exchange properties and partly resemble and partly don't resemble each other. In this world you can still tell the difference between persons and things, but the difference is not an ontological absolute.

This flattening is the most striking move made by that set of collaborations in the sociology of science that is sometimes known as actor network theory. The explicit focus of this group is on the subclass of things that might be called technological: the instruments of scientific work, on the one hand, and on the other the functional objects produced by the conjunction of scientific work with industry, with money, with engineers and designers, with markets and marketing strategies, with end-users, with planning and regulation, with legal rights and obligations, and so on. But may it not be that in some sense all objects belong to this class? That all objects are inscribed within worlds of meaning and use, that even the pebble has its uses and its meanings, among them that of figuring the useless and the meaningless? If so much depends upon a red wheelbarrow glazed with rain water beside the white chickens, is this not above all because there is something to say about it-namely, that so much depends upon it? Certainly Latour will argue that for all practical purposes (including, I think, the practical purposes of poetry) the absolute things 
of the discourse of thingness have no meaningful or indeed meaningless existence:

Objects that exist simply as objects, finished, not part of a collective life, are unknown, buried under soil. Real objects are always parts of institutions, trembling in their mixed status as mediators, mobilizing faraway lands and people, ready to become people or things, not knowing if they are composed of one or of many, of a black box counting for one or of a labyrinth concealing multitudes. ${ }^{20}$

It's not that, in the Marxist sense, things really are social relations which have become opaque; they both are and affect social relations, they are a partner in them, and all 'social' relations mix together chains of humans and nonhumans. Latour's exemplary objects-a speed bump, a hotel key with a weight attached to it, a door closer, a camera-are inscribed and programmed by human will and in turn, as nonhuman delegates, require humans to behave in certain ways. The speed bump is not made of matter, ultimately; it is full of engineers and chancellors and lawmakers, commingling their wills and their story lines with those of gravel, concrete, paint, and standard calculations.' Matter and persons connect and intermingle in a zone "where some, though not all, of the characteristics of concrete become policemen, and some, though not all, of the characteristics of policemen become speed bumps'. ${ }^{21}$

The metaphor of the chain or network is a way of trying to conceptualize the kinds of social actors (or perhaps more precisely actants) there are, the links that tie them together, and the systemic processes which constitute and configure them as actors. But to put it like this is to suggest that the network is a structuring context working upon actors already in possession of stable dispositions and interests. The point rather is that networks are formed by the relations and interactions between actors and in turn crystallize a morphology which shapes and constrains their interests and actions. Latour gives the example of the widespread uptake of photography following Eastman's invention of removable roll film in the late 1880s and asks whether we can explain this diffusion in terms of the interests of the social groups involved. But these groups, he argues, were themselves deeply transformed by the technical innovations: 'The amateur market [in photography] was explored, extracted, and constructed from heterogeneous social groups which did not exist as such before Eastman. The new amateurs and Eastman's camera co-produced each other.' ${ }^{22}$

20. Bruno Latour, 'On Technical Mediation-Philosophy, Sociology, Genealogy', Common Knowledge 3 (Fall 1994): 46.

21. Ibid., p. 41.

22. Latour, 'Technology Is Society Made Durable', trans. Gabrielle Hecht, in A Sociology of Monsters: Essays on Power; Technology, and Domination, ed. John Law (London, 1991), p. 117. 
The invention-in this case, Eastman's film stock and cameras-is an actor amongst others. It generates actions and changes relationships. But it doesn't do this by itself; it is not a determinant of change. The process is driven by all of the forces and interests involved-forces which are commercial, technological, legal, aesthetic, and so on-and which are invested unequally in players with different degrees of strength and persistence. If we think of an actor or actant in this sense as any entity with the power to associate chains of matter, text, humans and nonhumans, and money, then the reservation of the term to embodied human will becomes absurd; things, too, embody human will. The hotel key with a weight attached to it makes a polite request to me, on behalf of the hotelier, to hand it in at the desk before I go out. The speed bump gives me an instruction, on behalf of the police or some traffic control authority, to slow down on this stretch of road. To call these things, the key and the bump, 'nonhuman' is to ignore all the ways in which human will is translated into things and in which things in turn work as delegates which relay back to us these configurations of human will. 'Men and things exchange properties and replace one another': ${ }^{23}$ the microprocessor that transforms the Aramis light rail project is neither fully on the side of human beings, since it is inert matter onto which human qualities-reasonings, programmes of action, obedience and control-have been transcribed, nor fully on the side of nonhumans, since that transcription has made it more and other than 'a bag of parts, a heap of pins, a pile of silicon' ( $A$, p. 213). There are no such 'sides', such separate and selfcontained series; there is only an endless mixing of the properties of persons with the properties of things.

An important model for this ontology of the social order as a composite of 'networks of heterogeneous materials' is Foucault's conception of discourse (or rather the discursive formation) as a matter not of language alone but of a complex of talk, texts, rules, bodies, authorisations, things, architectures, and so on. ${ }^{24}$ The 'and so on' is important because the chains of relations that make up discourse and other institutions have no fixed composition and no predetermined effects. They are built from acts of translation-a process somewhat imprecisely defined in actor network theory but involving the recruitment and conversion of other (human or nonhuman) actors and chains of actors to one's own project in order to build more complex and more durable assemblages..5 Things, in this

23. Latour, Aramis, or The Love of Technology, trans. Catherine Porter (Cambridge, Mass., 1996), p. 61; hereafter abbreviated $A$.

24. Law, 'Introduction: Monsters, Machines and Sociotechnical Relations', in A Sociology of Monsters, p. 10.

25. See in particular Michel Callon, 'Some Elements of a Sociology of Translation: Domestication of the Scallops and the Fishermen of St Brieuc Bay', in Power, Action, and Belief: A New Sociology of Knowledge? ed. Law (London, 1986), pp. 196-233. 
model, never stand alone; they are bits of associative chains which form and re-form the hybrids of nature and culture of which our world is composed.

Things 'are simply vanishing', says Gadamer ('N', p. 71), but only if you mean 'a stone, a clod of earth, a piece of wood.' Is it really true that the world is becoming emptied of things? Karin Knorr Cetina makes precisely the opposite argument: that the modern world has seen an expansion not only of material things but of a 'sociality with objects' which has to some extent displaced forms of sociality centered on human beings. ${ }^{26}$ The problem again is that of the example: if Gadamer defines things against use, then artefacts don't count as proper things and the world is indeed emptier. But all things have uses, even if they are not designed to be useful. And all things are inscribed with textuality. This is quite clear in the case of artefacts. Every designed object is the end product of a process of talking, writing, sketching, and calculation. It is accompanied by 'codes, checklists, maintenance manuals and user handbooks'. ${ }^{27}$ And it bears within it the codes and programmes of action-the encoding of potential uses - that map its intended purposes. It goes without saying that these potential uses need not be realized. They may go astray, users may decline or be unable to recognize them, they may be deflected by other programmes, or they may be translated into contexts where they are unfamiliar or have no effective force. ${ }^{28}$ But artefacts, "carried on a wave of texts which bear testimony to the scars of the textualizations that accompanied their design and displacement,' ${ }^{29}$ are 'souls through and through' (A, p. 223).

All this is true a fortiori of the semantically and pragmatically most complex artefacts, those which function as works of art. Two kinds of complexity are immediately relevant. The first is that which has to do with the unpredictability of the relation between inscription and uptake, the uncontrollability of the reading process (which doesn't mean that it is unstructured, of course). The second has to do with the fact that works of art both are themselves things and may at the same time represent things. The doubleness of this relation to thingness is the ground of possibility for a form of self-reference whereby a meditation on things can be taken as a meditation on the thingness of the work of art; hence, perhaps, the poignancy of such meditation, as well as its urgency in raising the problem of the different kinds of thingness that may inhere in complex

26. Karin Knorr Cetina, 'Sociality with Objects: Social Relations in Postsocial Knowledge Societies', Theory, Culture, and Society 14 (Nov. 1997): 2.

27. Callon, 'Techno-economic Networks and Irreversibility', in A Sociology of Monsters, p. 137.

28. See Law, 'Power, Discretion, and Strategy', in A Sociology of Monsters, pp. 175-76.

29. Callon, 'Techno-economic Networks and Irreversibility', p. 137. 
functional artefacts, on the one hand, and simple or natural nonfunctional objects on the other.

If, privileging the latter, we were to reserve true thingness only to material entities, the problem of distinguishing the material from the immaterial dimensions of things would at once arise: are the programmes of action inscribed in a machine part of its thingness? Does the framing of a simple tool within a field or fields of possible uses detract from its materiality? Does the soul of the hawk, the biological coding of the thistle make it less thinglike than the pebble, 'equal to itself/mindful of its limits'? Can we distinguish meaningfully between objects which are fully cultural and objects which lack a cultural or at least artefactual dimension?

Alec McHoul tries to do so in a recent article. Defining the conditions of existence of the cultural object (by which he means 'whatever it is that people can produce-and-recognize as something', where 'recognize' means 'use-as' or 'know and use') ${ }^{30}$ by way of a contrast with naturally occurring objects, he writes that the former 'has meaning; it is a statement; it belongs to a cultural constituency; it's borrowable by other such agents for their own practices; it is assembled from several different technologies; and so on' ('OH', p. 21). And he gives as an example of the difference between naturally occurring and cultural objects the distinction 'between two otherwise identical piles of stones where one is a minor avalanche and the other a cairn' ('OH', p. 21). We might recognize this as the classic aesthetic problem of the Naturschönes, the nonintentional object which can be read as though it were intentional, and the problem, conversely, of the transformation effected on the pile of stones (or bricks, for example) by the imputation to it of an aesthetic intention. This topos restates in a different way the question of whether artefacts can be made to stand for all objects, or whether there is a difference in kind between pebbles and artefacts.

But look a little more closely at McHoul's specification of the conditions under which cultural objects can be recognized. Centrally, he says, they are characterized by the possibility that their 'propriety', their 'proper' or inscribed or intended function can be reappropriated, turned to a different use. Thus cultural objects are marked 'by the fact that they can always come to mean things, to be recognized, to be used, to be known, to be governed, and cared for in at least two (frequently more) different cultural systems, different assemblages of production and recognition' ('OH', pp. 10-11). Cultural and functional hybridity is an ordinary condition of objects, and the most mundane thing, a teacup for example, must be readable in a number of different ways-as an aesthetic object, as a useful object, as the material product of certain highly evolved tech- 
nologies, and so on. The teacup is inherently complex; it 'can only be known, used, recognized, and so on, because it can be so in relation to the confluence of more than a single system'. Conversely, if such things 'were ever given as hypothetically pure and simple productions and recognitions from within a single system, they wouldn't be knowable, usable or recognizable for us at all. (If there were such things, they would be noumenal, natural in the purest sense, and no art or science could know them)' ('OH', p. 12).

But this is just why there can be no neat distinction between cultural objects and naturally occurring objects. The pile of stones formed by a minor avalanche carries equally with it the possibility of being otherwise recognized; it can, for example, be taken for a cairn or taken to be beautiful. The condition of possibility is the same in each case. The stones, the pebble, exist within the realm of that possibility. Is there a difference, then, between the pile and the cairn? Yes, but it's one that, like that between humans and nonhumans, needs to be flattened, read horizontally as a juxtaposition rather than vertically as a hierarchy of being. It's a feature of our world that we can and do distinguish between piles of strewn stone and cairns, between pebbles and cameras, between trees and telegraph poles-between unintended and intended things, things shaped and unshaped-just as we routinely and reasonably distinguish things from persons. But the sort of world we live in makes it constantly possible for these two sets of kinds to exchange properties, for the heap of stones to be read as an arrangement, for the dead matter of the camera to be understood as an inscription of human work and will. The difference that seems to be one of kind is one of use and recognition. Conversely, of course, persons are and can be read as things (as bodies, as flesh and bone, living or dead). A discarded camera lying broken at the roadside or discarded on a beach can seem like driftwood, like mere scattered matter. The conversion from simple to complex, functional to nonfunctional, can happen in both directions. Things are naturally shifty, and part of how we think about them should involve the processes of recognition and framing which govern their placing, their point, their uptake. (And it is here that we might begin to catch sight of the limits of the example of the artefact that informs the network model of the being of things: the explanatory form to which it lends itself is that of an economy of uses, and it rarely adumbrates, except at the most general level, ${ }^{31}$ the historical dimensions of that economy. ${ }^{32}$ Rather, different models of

31. Latour sketches out a genealogy of the modernist principle of 'purification' which radically distinguishes people from things. See Latour, We Have Never Been Modern, trans. Porter (Cambridge, Mass., 1993).

32. The beginnings of such a detailed history are being worked out in a number of studies of technological development, of which the most striking is still Steven Shapin and Simon Schaffer, Leviathan and the Air-Pump: Hobbes, Boyle, and the Experimental Life (Princeton, N.J., 1985). 
the historicity of things are entailed by the example of the commodity, formed within a semiotic economy in which the mode of presence of things is deeply prestructured by the relation between model and series and between material things and their display or representation; or by the example of waste matter, formed by and formative of an economy of value for which it works as the exorbitant supplement that initiates change. $)^{33}$

Much of the most interesting writing on material culture in recent years has been concerned with the conversion processes by which things pass from one state into another. This includes the work of Igor Kopytoff and Arjun Appadurai on the complex trajectories of things in their passage from one regime of value to another; of Nancy Munn, Annette Weiner, and others on the multiple social functions performed by shell tokens in kula exchange; Nicholas Thomas's argument about the 'entanglement' of things, and systems of things, in the colonial encounter; and Michael Thompson's account of the way the zero-degree of value that he calls 'rubbish' works as a generative dynamic in the destruction and formation of value. ${ }^{34}$ These all lend support to Thomas's critique of 'the essentialist notion that the identity of material things is fixed in their structure and form' ${ }^{35}$ Things in any minimally complex system carry an indefinite number of actual or potential overlapping uses, significations, and values. No single game exhausts their function; no single description exhausts the uses to which their properties might appropriately or inappropriately lend themselves, and they are always shadowed by the traces of virtual uses and the complicated circuits of knowledge, need, and desire that map those virtualities.

A pebble, a camera, a man who turns into a telegraph pole. What kinds of things are these? The number of possible taxonomies is almost unlimited. Taxonomies inform and shape every sphere of life, from the plethora of folk classifications and the orderings of things by the law to the rigorous formal ontologies of the natural sciences and philosophy. ${ }^{36}$

33. See Frow, 'Invidious Distinction: Waste, Difference, and Classy Stuff', UTS Review (forthcoming).

34. See Igor Kopytoff, 'The Cultural Biography of Things: Commoditization as Process', in The Social Life of Things: Commodities in Cultural Perspective, ed. Arjun Appadurai (Cambridge, 1986), pp. 64-91; Appadurai, 'Introduction: Commodities and the Politics of Value', in The Social Life of Things, pp. 3-63; Nancy D. Munn, 'Gawan Kula: Spatiotemporal Control and the Symbolism of Influence', in The Kula: New Perspectives on Massim Exchange, ed. Jerry W. Leach and Edmund Leach (Cambridge, 1983), pp. 277-308; Annette B. Weiner, “A $A$ World of Made Is Not a World of Born”': Doing Kula on Kiriwina', in The Kula, pp. 147-70; Nicholas Thomas, Entangled Objects: Exchange, Material Culture, and Colonialism in the Pacific (Cambridge, Mass., 1991); and Michael Thompson, Rubbish Theory: The Creation and Destruction of Value (Oxford, 1979).

35. Thomas, Entangled Objects, p. 28.

36. See Geoffrey C. Bowker and Susan Leigh Star, Sorting Things Out: Classification and Its Consequences (Cambridge, Mass., 1999). 
But to speak briefly of the ways these things have appeared in the textual contexts in which I've cited them, we could say that if the pebble figures a fully nonhuman world, so entirely and indifferently other that it turns, by a familiar paradox, into a quasi subject in its own right; if the throwaway camera is a black box which opens out to reveal the weave of stories and travels and tracings of work and trade that compose it; and if the man who turns into a telegraph pole speaks to us of the passing of the human and the nonhuman backwards and forwards between and into each other, these three things do not belong to mutually exclusive classes. Rather than thinking in terms of an opposition of things to humans or of inanimate material entities to bodies endowed with consciousness and intention, it makes sense to recognize both the heterogeneity of things in the world-complexly ordered along intersecting scales running from the material to the immaterial, the simple to the complex, the functional to the nonfunctional, the living to the inert, the relatively immediate to the highly mediated-and the fluidity of the relations between these categories. Thingness and the kinds of thingness are not inherent in things; they are effects of recognitions and uses performed within frames of understanding (which may be markets or ad hoc negotiations of action or desire or bodily skills as much as they may be intellectual formattings or sedimented codes). And persons, too, count or can count as things. This is the real strangeness: that persons and things are kin; the world is many, not double. 


\section{University Library}

\section{- M M I N E R VA A gateway to Melbourne's research publications}

Minerva Access is the Institutional Repository of The University of Melbourne

Author/s:

FROW, JOHN

Title:

A pebble, a camera, a man who turns into a telegraph pole

Date:

2001

Citation:

Frow, J. (2001). A pebble, a camera, a man who turns into a telegraph pole. Critical Inquiry, 28(1), 270-285.

Publication Status:

Published

Persistent Link:

http://hdl.handle.net/11343/34483 